\title{
A Santa Sé e os impasses da modernidade
}

\author{
William de Souza Martins*
}

Rust, Leandro Duarte. Mitos papais: política e imaginação na História. Petrópolis: Vozes, 2015.

Há um século, o historiador Benedetto Croce elaborou uma análise que marcou posteriormente diversas interpretaçóes. Afastando-se da perspectiva segundo a qual a História contemporânea abrangeria apenas o passado muito próximo ("os cinquenta últimos anos, o último decênio, o último ano, mês ou dia ou mesmo a última hora ou minuto"), o erudito italiano entendeu que os fatos do presente mantinham relaçôes próximas com diferentes temporalidades históricas: "somente uma preocupação da vida presente pode nos impelir a fazer pesquisas sobre um fato do passado". Ou, dito de modo mais claro: "a contemporaneidade não é própria de uma categoria de histórias (...), mas caracteriza intimamente toda a história”. ${ }^{1}$

As consideraçóes desenvolvidas parecem adequadas para introduzir a discussão do novo livro de Leandro Duarte Rust,

\footnotetext{
${ }^{1}$ CROCE, Benedetto. Théorie et histoire de l'historiographie [1915]. Genève: Droz, 1968, p. 13-14. Grifos do autor.
}

professor de História Antiga e Medieval da Universidade de Mato Grosso, e autor, entre outras obras, de as Colunas de São Pedro: a política papal na Idade Média Central (São Paulo: Annablume, 2011). Buscando atingir simultaneamente o público acadêmico e o leitor não especializado interessado nas investigaçóes históricas, o autor se propóe a analisar o que designa como "mitos papais", quais sejam: o suposto pontificado de São Pedro, o apóstolo; o Cristianismo Primitivo; a Reforma Gregoriana; o papado de Alexandre VI, da família Bórgia; e o pontificado de Pio XII, que recentemente recebeu o cognome de "papa de Hitler".

Não se trata assim de uma história linear da Igreja, como muitas já disponíveis. O leitor tem em mãos uma obra construída em torno de um problema de pesquisa bem delimitado. Além disso, salta aos olhos a habilidade do autor em alternar diferentes temporalidades históricas, indo do cristianismo dos primeiros tempos até o século XX, sem perder o fio da narrativa. Este modo de narrar resulta da forma como os mitos papais foram construídos. Nos cinco casos analisados, trata-se de narrativas estruturadas aproximadamente entre $1870 \mathrm{e}$

DOI - http://dx.doi.org/10.1590/2237-101X0173217

* Universidade Federal do Rio de Janeiro (UFRJ). Rio de Janeiro, RJ, Brasil. E-mail: williamsmartins@uol.com.br Doutor em História Social pela Universidade de Sáo Paulo e professor da Universidade Federal do Rio de Janeiro (UFRJ). Rio de Janeiro, RJ, Brasil. E-mail: williamsmartins@uol.com.br 
2000, período em que a Igreja se viu diretamente desafiada pelos processos resultantes da Modernidade, conforme será detalhado. Um dos argumentos centrais do autor é que tais narrativas mitológicas cumpriram a funçáo de redefinir de maneira positiva o lugar da Igreja católica em geral, e da Santa Sé em particular, em um período marcado pela perda da sua influência social e política. A produção das referidas narrativas não foi obra de erudição desinteressada, resultando antes da necessidade de assumir posiçóes políticas para combater projetos de poder rivais. Os mitos papais foram construídos no calor dos acontecimentos dos séculos XIX e $\mathrm{XX}$, deixando-se impregnar pela contemporaneidade de que Benedetto Croce falava.

Antes de passar ao comentário dos mitos escolhidos pelo autor, cada um ocupando um capítulo à parte no livro, deve-se dialogar com a definiçáo de mito utilizada na obra. $\mathrm{O}$ autor se baseia na análise de Christopher G. Flood, para quem os

Mitos políticos são perspectivas assumidas sobre a autoridade e a dominação, a resistência e a exclusão, a unidade e a separaçáo. Quando narrativas deste tipo surgem conectadas, circulando em uma mesma época como armas empregadas na luta pelo controle do comportamento coletivo, elas formam uma mitologia política. (p. 27)

Mais conhecida pela historiografia brasileira, a obra de Raoul Girardet, Mitos e mitologias políticas, aparece citada somente de maneira pontual, para tratar da importância do apelo à unidade em tempos de crise (p. 71-72). Náo obstante, a análise do professor Leandro Rust ganharia amplitude caso tivesse recorrido com maior frequência à obra do estudioso francês. A interpretação que Girardet propóe do mito político, segundo a qual este cumpre uma tripla função, a de fabulação, a de explicação e a de mobilização, se torna basilar para compreender as tramas conspiratórias e os complôs produzidos em série ao longo dos séculos XIX e XX, de que constituem exemplo as perseguições promovidas contra os judeus e os jesuítas. ${ }^{2}$ Sem dúvida, a gênese da produçáo deste tipo de mitologia política se situa um pouco mais além, no âmbito do imaginário das Luzes e da Revoluçáo Francesa. A apropriação de alguns elementos do primeiro por parte de algumas monarquias setecentistas levou-as a medidas contrárias à Companhia de Jesus, que culminaram com a supressão da Ordem em 1773 pela Santa Sé. ${ }^{3}$ Além disto, esta se viu ameaçada com o corte de relaçóes diplomáticas, como o que foi praticado por Portugal, entre 1759 e $1770 .{ }^{4}$ No que tange à importância dos eventos políticos da França para a produçáo de mitos, pode-se assinalar a contribuição de François Furet, segundo

${ }^{2}$ GIRARDET, Raoul. Mitos e mitologias politicas. São Paulo: Companhia das Letras, 1987, p. 9-62.

${ }^{3}$ A respeito dos discursos mitológicos envolvendo especificamente a Companhia de Jesus, ver FRANCO, José Eduardo. O mito dos jesuitas em Portugal, no Brasil e no Oriente (séculos XVI a XX). Lisboa: Gradiva, 2006, v. 1, p. 19-45; WRIGHT, Jonathan. Os jesuitas: missóes, mitos e histórias. Rio de Janeiro: Relume Dumará, 2006, p. 137-194.

${ }^{4}$ MILLER, Samuel J. Portugal and Rome, c. 17481830: An Aspect of the Catholic Enlightenment. Roma: Università Gregoriana Editrice, 1978, p. 232-245. 
a qual a temida "conspiração aristocrática", denunciada pelas lideranças revolucionárias, tornava-se a imagem invertida da ideologia democrática e igualitária promovida pela própria Revolução. ${ }^{5} \mathrm{Na}$ sequência do processo revolucionário, e tornando-se porta-voz dos ideais laicizantes e republicanos da França, Napoleão Bonaparte ensejou uma farta produção de leituras e imagens míticas, "ancoradas seja na luta entre o bem e o mal, seja na perspectiva da vinda de um salvador, seja no regresso a uma idade de ouro, seja ainda, especialmente, na visão do anticristo". ${ }^{6}$

Parece válida a chave interpretativa proposta por José D’Assunção Barros no Prefácio da obra, segundo o qual os mitos papais se situam nas "tensóes produzidas pelas relações do papado com a Modernidade" ( $p$. 17). Esta última deve ser compreendida no seu significado histórico e filosófico mais amplo de ruptura com a tradição: "a modernidade não pode e não quer continuar a ir colher em outras épocas os critérios para a sua orientação, ela tem que criar em si própria as normas por que se rege". Segundo a conhecida análise de Koselleck, as condições para a afirmação plena da Modernidade foram dadas na segunda metade do século XVIII, quando o horizonte de expectativas dos sujeitos históricos se distanciava cada vez mais do espaço de experiência em que tinham sido formados, criando uma dinâmica de

5 FURET, François. Pensar a Revolução Francesa [1978]. Lisboa: Ed. 70, 1988, p. 80-84.

${ }^{6}$ NEVES, Lúcia Maria Bastos Pereira das. Napoleão Bonaparte: imaginário e política em Portugal (c. 1808-1810). São Paulo: Alameda, 2008, p. 29.

${ }^{7}$ HABERMAS, Jürgen. $O$ discurso filosófico da modernidade. Lisboa: Dom Quixote, 1990, p. 18. Grifos do autor. aceleração e de descontinuidade do tempo histórico. ${ }^{8}$ Ainda que o próprio autor não tenha recuado até o século XVIII para situar a perda de poder político e social da Igreja de Roma, talvez seja útil reconstituir aqui este contexto mais amplo para aprofundar a compreensão dos "mitos papais".

Cabem também algumas palavras gerais sobre a composição da narrativa do autor. Em cada capítulo, é analisado um mito político particular a respeito da Santa Sé. O autor mostra convincentemente que narrativas míticas que evocavam pontificados da Antiguidade, da Idade Média e do Renascimento foram construídas muito tempo depois dos referidos acontecimentos ou, mais exatamente, entre 1870 e o pós-Segunda Guerra Mundial. Por trás da elaboração dos referidos relatos, situavam-se estudiosos e historiadores comovidos com o impacto das consequências da Modernidade sobre o poder da Igreja e do pontífice romano, como pilares dos valores da tradição e da cultura do Ocidente. Após a exposição das narrativas míticas, o autor promove a desconstrução das mesmas, valendo-se de farto material crítico, constituído por contribuiçóes da historiografia especializada e por fontes de natureza muito variada. A partir das operaçóes complementares de contextualização, de exposição dos mitos e da crítica, o autor fornece aos leitores valiosas pistas, que poderão levá-los a construir suas próprias visões sobre os papados em foco, atingindo o objetivo da obra historiográfica aberta a su-

\footnotetext{
${ }^{8}$ KOSELLECK, Reinhart. "Espaço de experiência" e "horizonte de expectativa": duas categorias históricas. In: KOSELLECK, Reinhart. Futuro passado: contribuição à semântica dos tempos históricos. Rio de Janeiro: Contraponto: Ed. PUC-Rio, 2006, p. 305-327.
} 
cessivas contribuiçôes e reinterpretaçôes.

No primeiro capítulo, a autor discute o mito do pontificado de São Pedro. Ainda que os Evangelhos atribuam a Jesus a frase "também eu te digo que tu és Pedro, e sobre esta pedra edificarei minha Igreja” (Mt, $16,18)$, está longe de consenso historiográfico a hipótese de que Pedro tenha sido o primeiro papa e fundador da Igreja de Roma. Não obstante, ao longo da Segunda Guerra Mundial, o papa Pio XII (1939-1958) promoveu escavações no subsolo da Basílica de São Pedro, a fim de obter informaçôes que pudessem comprovar a atuação do apóstolo como primeiro pontífice. Em 1950, um relatório elaborado por uma equipe de arqueólogos e estudiosos convenceu o papa de que havia indícios suficientes sobre a descoberta da tumba e dos restos mortais do apóstolo. Esta última informação, bem mais difícil de auferir, foi encampada pela arqueóloga Margherita Guarducci, da Universidade de Roma. Para tanto, a estudiosa se baseou em diversas fontes, que são cuidadosamente apresentadas e contextualizadas pelo autor. Guarducci se apoiou também nos testemunhos das inscriçóes contidas na suposta tumba do apóstolo. Em diálogo crítico com a referida interpretação, o professor Leandro Rust mostra que as fontes citadas podem ser lidas de diversas maneiras, relativizando as conclusóes da pesquisadora italiana. No pós-guerra, período marcado pela crise dos valores da civilização ocidental, a Santa Sé, amparada na pesquisa de diversos estudiosos, buscou se fortalecer por meio do mito do pontificado de Sáo Pedro.

O conceito de "Cristianismo Primitivo" constitui o segundo mito analisado pelo autor. Ao longo do século XX, tanto na imprensa como em obras de natureza historiográfica, tornou-se corrente o uso daquela expressáo para caracterizar o cristianismo dos primeiros tempos. De modo mais exato, o cristianismo dos três primeiros séculos, anteriores à ascensão de Constantino, que oficializou o culto cristáo no âmbito do Império Romano. Além de encerrar definitivamente as perseguiçóes dirigidas aos cristãos, o édito de Constantino teve o efeito de afastar os bispos da comunidade dos fiéis, acentuando as divisões hierárquicas na instituição eclesiástica, e de preparar o terreno para a posiçáo central do bispo de Roma sobre toda a Igreja. Em contraste, segundo Max Weber, o "Cristianismo Primitivo" caracterizou-se pela "rejeição antipolítica do mundo", isto é, "uma religiosidade voltada para a redenção através da fraternidade, da renúncia material, do repúdio à violência e da diferença perante o Estado" (p. 83).

$\mathrm{O}$ autor apresenta diversos elementos que matizam a tese weberiana, diminuindo os contrastes entre os períodos situados antes e depois da decisão de Constantino. Uma parte das elites imperiais já havia se cristianizado antes do ano 200. Outros indícios mostram que os cristáos tinham adotado previamente um código social mais pragmático, acomodado ao status quo. Em 197, o sacerdote Tertuliano defendeu a compatibilidade entre o cristianismo e a defesa dos poderes imperiais. De maneira complementar, o professor Leando Rust refuta a ideia de que o bispo de Roma teria assumido um poder centralizador 
sobre toda a Igreja, imediatamente depois das medidas de Constantino. Adotando o código moral das elites romanas, baseado na autoridade do pater familias e na exaltação da piedade, da castidade e da moderação, a autoridade dos pontífices romanos foi construída a partir de outras bases: "nos últimos séculos do mundo antigo, se outros bispos os obedeciam não era porque os enxergavam como líderes estatais ou soberanos, mas porque viam em suas açóes e em sua retórica a patria potestas, ou seja, o poder paternal" (p. 103).

No terceiro capítulo, o autor traz à discussão o tema da Reforma Gregoriana, que foi primeiramente elaborado na tese de doutorado de Augustin Fliche, publicada na década de 1920. De acordo com este erudito, sob a ameaça dos poderes dos senhores feudais e o do imperador, que interferiam diretamente na escolha dos bispos, o papa Gregório VII (1073-1085) tomou uma série de decisóes, estabelecendo que somente o pontífice romano possuía a autoridade para a investidura dos bispos. Esta e outras medidas estabeleceram o primado do poder espiritual sobre os poderes temporais, transformando a Igreja em um protótipo de monarquia centralizada, responsável pela ordem pública e pela moralização da sociedade. O professor Leandro Rust salienta que a tese da Reforma Gregoriana se tornou um poderoso mito papal, cuja repercussão se encontra presente em contribuições historiográficas recentes. Elaborada em um contexto marcado pela derrocada dos impérios russo, Habsburgo e Otomano, a tese traz a marca de um pensamento tradicionalista, temeroso diante de um quadro político em que "as instituiçóes estavam desacreditadas; a ordem, espatifada; a lei, desacatada" (p. 115). O mito da Reforma Gregoriana vinha reforçar o papel da Igreja como guardiá da unidade e da tradição, em uma época conturbada. Além de situar o contexto de produçáo do mito, o autor desenvolve um exercício semelhante ao praticado nos capítulos precedentes, mostrando que a suposta "monarquia papal" do século XI era mais frágil e incerta do que se imagina: "o papado comandado por Gregório VII não foi uma monarquia centralizada capaz de inaugurar uma época inteiramente nova. Ele foi uma instituição feudal, repleta de tensôes e de limitações, como o mundo que a abrigava" (p. 139).

O quarto capítulo do livro analisa o pontificado de Alexandre VI (1492-1503), da família Bórgia. A fama negativa deste papado se deve à "lenda negra" construída em torno do cardeal Rodrigo Bórgia e de seu clã espanhol, que permanece arraigada até os dias atuais, a ponto de se considerá-lo "o pior papa da história” (p. 169). De acordo com o mito papal em questão, a corrupção da conduta moral da cúpula da Igreja e o favorecimento de parentes atingiram o clímax no pontificado de Alexandre VI. A própria eleiçáo do papa foi marcada pela denúncia da compra de votos no colégio dos cardeais. Conforme assinala o autor, o mito em questão foi lavrado por Ferdinand Gregorovius. A obra $A$ história de Roma na Idade Média foi redigida em 1870 pelo erudito alemáo sob o impacto da perda dos territórios da Santa Sé para o Estado italiano e da proclamaçáo do dogma da infalibilidade papal no Concílio Vaticano I, convocado por Pio IX (1846-1878). Adepto do ideal nacionalista, 
Gregorovius atribuía à "tirania" dos papas a ausência de unidade política na península italiana, colocando no mesmo plano o domínio estrangeiro dos Bórgia e o "despotismo" absoluto do papa Pio IX (p. 153 e 184).

Em contraste com as avaliaçóes parciais do pontificado de Alexandre VI, o autor busca entendê-lo a partir dos condicionamentos coevos. Assim, "o favorecimento da própria família cumpria uma função política: redirecionando recursos da Igreja para filhos e parentes, o Papa Bórgia estruturava um grupo leal à sua autoridade" (p. 178). Ademais, estudos recentes a respeito do período do Renascimento e do Antigo Regime têm mostrado a importância dos vínculos de sangue na formação de redes de poder de famílias aristocráticas, em que a ocupação de posiçóes no alto clero e na carreira eclesiástica em geral assumiam uma posição estratégica. ' Por fim, o autor mostra a ligação entre a imagem inteiramente negativa do pontificado de Alexandre VI com a "lenda negra" de tradicionalismo e obscurantismo associada à cultura ibérica (p. 185). Neste caminho, valeria a pena ter dialogado mais com a historiografia dos mitos políticos construídos em torno da Companhia de Jesus e da Inquisição, instituiçôes eclesiásticas marcadas simultaneamente pela herança ibérica e pela vinculação à Santa Sé. ${ }^{10}$

\footnotetext{
9 MONTEIRO, Nuno Gonçalo. Poder senhorial, estatuto nobiliárquico e aristocracia. In: HESPANHA, António Manuel (Coord.). O Antigo Regime (1620-1807). Lisboa: Estampa, 1993, p. 332-379; LAVEN, Mary. Virgens de Veneza: vidas enclausuradas e quebra de votos no convento renascentista. Rio de Janeiro: Imago, 2003, p. 67-83.

10 PROSPERI, Adriano. Tribunais da consciência: inquisidores, confessores, missionários. São Paulo: Edusp, 2013, p. 189-211, a respeito da "lenda negra" da Inquisição. A respeito dos jesuítas, ver a nota 3 acima.
}

No quinto capítulo, o autor discute o silêncio do papa Pio XII (1939-1958) diante das atrocidades cometidas pela Alemanha nazista. De acordo com o referido mito político, "traumatizado pelo envolvimento judaico com a luta política de 1918-1919, identificado com a cultura alemã e obcecado por fazer carreira no interior da Cúria Romana, Pacelli teria optado por uma conciliação com o nazismo" (p. 200). A tese foi difundida por John Cornwell na obra O papa de Hitler: a história secreta de Pio XII, publicada no Brasil em 2000. Pacientemente, o autor desmonta os argumentos do silêncio do papa. Sem exército e com um território mínimo, o Estado do Vaticano contava apenas com os canais diplomáticos como instrumentos de pressão externa. Em encíclicas publicadas em 1937 e em 1939, o papa condenou o antissemitismo, a exaltação da raça e a invasão da Polônia pelo exército de Hitler. Durante a Segunda Guerra, com a Itália ocupada pelas tropas alemãs, a Santa Sé mudou o tom das condenaçôes formais, recorrendo à resistência indireta e fluida. Milhares de judeus foram poupados dos campos de concentração ao se abrigarem em estabelecimentos católicos, cuja imunidade tinha ficado assegurada pela concordata estabelecida em 1933 entre a Alemanha e o Vaticano, representado pelo cardeal Eugenio Pacelli, o futuro Pio XII.

Por trás dos mitos analisados, o autor mostra a existência de uma lógica simplista e maniqueísta que, derivada dos embates políticos, se revela incapaz de perceber as nuances e complexidades presentes no processo histórico. $\mathrm{O}$ livro constitui um ótimo exercício de como construir e descontruir histórias, e tem o mérito de se colocar ao alcance do público náo especializado ou que está principiando os estudos na área. 